\title{
Thermopower and Hall Effect in silicon nitride composites containing thermally reduced graphene and pure graphene nanosheets
}

\author{
C. Ramirez ${ }^{1}$, V. Leborán ${ }^{2}$, F. Rivadulla 2 , P. Miranzo ${ }^{1}$, M. I. Osendi ${ }^{1 *}$ \\ ${ }^{1}$ Institute for Ceramics and Glass (ICV-CSIC), Madrid, Spain \\ ${ }^{2}$ Centro de Investigación en Química Biológica y Materiales Moleculares \\ (CIQUS), Universidad de Santiago de Compostela, 15782-Santiago de \\ Compostela, Spain.
}

${ }^{*}$ Corresponding author email: miosendi@icv.csic.es (M.I. Osendi) Phone: +34 917355840, Fax: +34 917355843

\section{Keywords}

Graphene, graphene oxide, ceramics, $\mathrm{Si}_{3} \mathrm{~N}_{4}$, thermopower, Hall effect, STEM, $\mathrm{N}$-doping, nanoclusters

\section{Abstract}

Composites consisting of dielectric silicon nitride $\left(\mathrm{Si}_{3} \mathrm{~N}_{4}\right)$ with diverse percentages of different graphene nanoreinforcements, such as graphene nanoplatelets (GNP) -17 and 21 vol.\%- and reduced graphene oxide (rGO) sheets -4 and 7 vol.\%- displayed thermopower effect. Maximum thermopower was observed for the rGO containing composites, which reached a peak Seebeck coefficient (S) of $-26 \mu \mathrm{V} . \mathrm{K}^{-1}$ at $300 \mathrm{~K}$, whereas GNP composites showed top $S$ of $+5 \mu \mathrm{V} . \mathrm{K}^{-1}$ at the same temperature. Hall effect measurements indicated that current carriers were different in both composites, electrons for the $\mathrm{rGO} / \mathrm{Si}_{3} \mathrm{~N}_{4}$ (n-type conductor) and holes for the GNP/Si3 $\mathrm{N}_{4}$ materials (p-type conductor) and also having $~ 1.4$ times higher carrier concentration the first composites. The enhanced thermopower of the $\mathrm{rGO} / \mathrm{Si}_{3} \mathrm{~N}_{4}$ composites is attributed to the particular defective nature of rGO sheets, which presented edge defects and nanometer scale defect clusters as shown by the high 
resolution images - probably associated to both oxygen atoms remaining after $\mathrm{GO}$ reduction during spark plasma sintering and $\mathrm{N}$ doping from the $\mathrm{Si}_{3} \mathrm{~N}_{4}$ matrix.

\section{Introduction}

One of the routes to create new thermoelectric materials consist in nanostructuring, hence reducing thermal conductivity through phonon scattering, while maintaining a high electrical conductivity $[1,2]$. The sintering of nanopowders is an alternative route for reducing thermal conductivity by creating multiple interfaces, which also offers the opportunity of improving the poor mechanical properties of most thermoelectric materials [3].

The performance of a thermoelectric material is accounted by the dimensionless figure of merit $Z T$, defined as $S^{2} \sigma T / \kappa$, where $S$ is the Seebeck coefficient, $\sigma$ the electrical conductivity, $\kappa$ the thermal conductivity and $T$ the absolute temperature. The upper ZT value for commercial thermoelectric materials stays $\sim 1$ and most works in the field aim at raising this value, which is not trivial as the parameters involved are mutually dependent [1].

The single layer graphene (SLG) exhibits high electrical conductivity and high carrier mobility [4] in addition to thermopower effect, with reported peak S values in the range $50-80 \mu \mathrm{V} \cdot \mathrm{K}^{-1}$ at $300 \mathrm{~K}[5,6]$, which gives large power factors -defined as $\mathrm{PF}=\mathrm{S}^{2} \sigma-$ for this material. However, the thermal conductivity of SLG $\left(\sim 4000 \mathrm{~W} \cdot \mathrm{m}^{-1} \mathrm{~K}^{-1}\right)$ [7] should be significantly reduced for practical thermoelectric applications [8]. In fact, ZT values for pristine graphene are in the range 0.1-0.01 [9], far from the target value of 1 . 
Xiao et al. [10] confirmed a substantial increase of the high temperature Seebeck coefficient up to $700 \mu \mathrm{V} . \mathrm{K}^{-1}$-reaching a maximum power factor of 4.5 $\mathrm{mW} \cdot \mathrm{m}^{-1} \mathrm{~K}^{-2}$ at $575 \mathrm{~K}$ - when they treated few layer graphene (FLG) films under an oxygen plasma. Authors explained this enhancement by an effective opening of the electronic band-gap [11] through the generation of disordered carbon spots instead to the presence of oxygen functional groups. They supported this assumption on the much smaller PF, between $0.8-3.6 \mu \mathrm{W} \cdot \mathrm{m}^{-1} \cdot \mathrm{K}^{-2}$, they observed for $2 \mathrm{~nm}$ thick films of reduced with hydrazine with maximum $\mathrm{S}$ of +15 $\mu \mathrm{V} \cdot \mathrm{K}^{-1}$ at $300 \mathrm{~K}$ and upper limit $\sigma$ of $8 \times 10^{3} \mathrm{~S} \cdot \mathrm{m}^{-1}$ at $525 \mathrm{~K}$.

Recent studies [11] on GO paper of around $100 \mu \mathrm{m}$ of thickness, with variable grades of chemical reduction, showed $\mathrm{S}$ values in the range $10-60 \mu \mathrm{V} \cdot \mathrm{K}^{-1}$ at room temperature that increased with the amount of oxygen in the specimens. Thus, the maximum thermopower corresponded to the more oxidized specimen that consequently showed the minimum $\sigma \sim 0.1 \mathrm{~S} \cdot \mathrm{m}^{-1}$. Diminishing the amount of oxygen augmented very effectively $\sigma$ but at the expenses of a lower $S$. Accordingly, the highest PF $\left(\sim 0.11 \mu \mathrm{W} \cdot \mathrm{m}^{-1} \cdot \mathrm{K}^{-2}\right)$ was achieved for the more reduced specimens which showed a $\mathrm{S}$ of $+10 \mu \mathrm{V} . \mathrm{K}^{-1}$-being both data close to the values reported above for rGO films- and therefore they could be taken as representative of chemically top reduced GO.

On the other hand, theoretical calculations predict important increases in S coefficient by methods like nanopatterning of the graphene surface for example by chemical functionalization [9], which basically increases the density of states near the band edge. 
It is known that graphene fillers can render electrical conductivity to originally insulator matrices, polymers [12] as well as ceramics [13]. Hence, seems coherent to investigate if something similar occurs with the thermoelectric effect in composites containing graphene in concentrations above the percolation limit to assure a contacted graphene network. In this respect, studies on the thermoelectric properties of composites with graphene fillers are scarce. Particularly, we can mention the works on polyaniline with $50 \mathrm{wt} . \%$ graphene nanoplatelets (GNPs) and polyaniline with 30 wt.\% graphite oxide (GO) flakes, which gave values of the thermoelectric power at room temperature $[14,15]$ between 33-40 $\mu \mathrm{V} . \mathrm{K}^{-1}$ (power factor, $\sim 5.6-10 \mu \mathrm{W} \cdot \mathrm{m}^{-1} . \mathrm{K}^{-2}$ ) and $\sim 25 \mu \mathrm{V} . \mathrm{K}^{-1}$ (power factor $0.4 \mu \mathrm{W} \cdot \mathrm{m}^{-1} \cdot \mathrm{K}^{-2}$ ), respectively.

Focusing on graphene/ceramic materials, we can point out the work [16] on tetragonal zirconia ceramics (3Y-TZP) with $2.65 \mathrm{wt} . \%$ of GO -partially reduced during sintering- giving S -15 $\mu \mathrm{V} \cdot \mathrm{K}^{-1}$ and power factor of $0.12 \mu \mathrm{W} \cdot \mathrm{m}^{-1} \cdot \mathrm{K}^{-2}$ at 300K. As antecedent we could mention the work by Zhan et al [17] on 3Y-TZP with single wall carbon nanotubes (SWCNT) that reported a maximum $S$ of $\sim 30$ $\mu \mathrm{V} . \mathrm{K}^{-1}$ at $350 \mathrm{~K}$ and $\mathrm{PF}$ around $3 \mu \mathrm{W} \cdot \mathrm{m}^{-1} \cdot \mathrm{K}^{-2}$ at $350 \mathrm{~K}$ for the $10 \mathrm{vol} . \%$ of SWCNT composite. If we include genuine thermoelectric materials in the scope of ceramic composites, there is also a recent publication [18] on a high temperature thermoelectric ceramic hybrid such as Al-doped $\mathrm{ZnO}$ with $1.5 \mathrm{wt} . \%$ of chemically reduced $\mathrm{GO}$ that stated a decrease of $\mathrm{S}$, in absolute value, at 1173K from 200 to below $100 \mu \mathrm{V}$. $\mathrm{K}^{-1}$ with the $\mathrm{rGO}$ addition, although an $60 \%$ increase in ZT (0.28) was measured due to the induced increase of $\sigma$ and the reduction in $\kappa$. Similarly, in the case of a Lanthanum Strontium Titanium Oxide 
thermoelectrics a decrease of $\mathrm{S}$ coefficient is also reported for GO additions from 400 to $100 \mu \mathrm{V}$. $\mathrm{K}^{-1}$ - with a relatively high power factor $\left(\sim 2500 \mu \mathrm{Wm}^{-1} \mathrm{~K}^{-2}\right)$ and figure of merit $(Z T=0.42)$ at room temperature, also because of the reduction in $\kappa$ and the improvement of $\sigma[19]$.

It has been shown that graphene/ $\mathrm{Si}_{3} \mathrm{~N}_{4}$ composites are remarkable composites regarding toughness and strength properties [20-21], have outstanding electrical conductivity [22] and also produce a decline of the thermal conductivity depending on the crystallinity and the orientation of the graphene stacks [2224]. In this paper we report for the first time the occurrence of thermoelectric effect for these composites, probing not only various volume concentrations but also two sorts of fillers (thermally reduced GO and pristine GNPs differing in the number of defects and degree of exfoliation). In this way, we determine the impact of the graphene characteristics on the Seebeck coefficient from $100 \mathrm{~K}$ to room temperature. The carrier type and concentration are also determined by measurement of the Hall effect for both composite types. As we are dealing with an electrically insulating matrix, the difference observed in the thermoelectric behavior allows without ambiguity its ascription to the particular characteristics of the graphene fillers.

\section{Experimental Procedure}

Two kinds of ceramic composites were prepared using GNPs and GO sheets, respectively, following the same route described elsewhere $[22,25]$. In short, the matrix composition was a blend of $\alpha-\mathrm{Si}_{3} \mathrm{~N}_{4}$ (E-10, Ube Corp.) plus 2 wt.\% $\mathrm{Al}_{2} \mathrm{O}_{3}$ (Baikalox-SM8) and $5 \mathrm{wt} \% \% \mathrm{Y}_{2} \mathrm{O}_{3}$ (HC-Stark) powders, these oxides acting as sintering aids. GNPs are commercial nanoplatelets (N002 from Angstron 
Materials) of nominally $0.2 \mu \mathrm{m}$ diameter and $1 \mathrm{~nm}$ thickness. The nanoplatelets were highly agglomerated in the as received state; accordingly they were dispersed in isopropyl alcohol using a sonication bath before mixing them with the dispersion of the ceramic powders also in same alcohol media. GO sheets, prepared by the modified Hummers method, were re-dispersed in ethanol and blended with the matrix by sonication and blade mixing. The different alcohol media for GNP and GO dispersions was based on stabilization tests. The GNP and GO dispersions were drop cast on glass slides for observation in the scanning force microscope (SFM, Nanotec) for filler thickness evaluations. Densification took place by spark plasma sintering (SPS) (Dr. Sinter, SPS $510 \mathrm{CE}$ ) at $1625^{\circ} \mathrm{C}$ for $5 \mathrm{~min}$, applying $50 \mathrm{MPa}$ of uniaxial pressure and under vacuum of $4 \mathrm{~Pa}$. Four different specimens -disks of $20 \mathrm{~mm}$ diameter and $\sim 3$ $\mathrm{mm}$ thick- were prepared, two of them with 4 and $7 \mathrm{vol} . \%$ of $\mathrm{rGO}$, and the other two having 17 and 21 vol.\% of GNPs, respectively. All the composites achieved full densification (>99.7\% of theoretical). The dissimilar volume concentrations for GNP and rGO composites are justified by their thickness differences; accordingly, for the thicker fillers, GNPs, a higher volume concentration was needed to achieve an electrically contacted network $[22,25]$.

Field emission scanning electron microscopy (FE-SEM, S-4700 Hitachi, Japan) was used to analyze the microstructure of the specimens. Raman spectra were recorded (WITec spectrometer, Alpha-300) at a laser excitation wavelength of $532 \mathrm{~nm}$. Raman scans of $100 \times 100$ points and $60 \mathrm{~ms}$ acquisition time per spectrum were recorded in polished areas of $10 \times 10 \mu \mathrm{m}^{2}$. The microstructure at higher resolution of the $4 \mathrm{vol}$. \% rGO composite was observed in a microscope Jeol JEM ARM 200cF with aberration correction of condenser lens able to work 
in TEM and STEM (scanning transmission electron microscopy) modes and HAADF (High-angle annular dark-field) conditions. Specimen was prepared by dimple grinding and ion milling methods.

Different thermal gradients were applied with a ceramic resistor attached to the samples (see scheme in Fig. 1) to measure the Seebeck coefficient. The induced temperature difference and thermal voltage were recorded at each base temperature with a difference thermocouple and $\mathrm{Cu}$ wires, respectively. The measurements were performed under vacuum between 100 and $325 \mathrm{~K}$. The carrier density was determined from measurements of the Hall effect in thin square-shaped sections of each sample. The samples were contacted in the corners, in a Van der Paw configuration. Room temperature electrical and thermal conductivities measured in the two types of the specimens were used to compare the PF and ZT of each specimen. The dc electrical conductivity was determined using four-probe and the thermal conductivity was calculated from the thermal diffusivity measured by the laser flash method. In the case of the 7 vol.\% rGO and 21 vol. \% GNP specimens, the conductivity was appraised using simple thermal resistance models and the conductivities of the matrix and reinforcements. Both properties were determined for the same specimen orientation than stated for the $\mathrm{S}$ measurements, i.e. in-plane orientation of the graphene nanostructures and data provided here are the same as those reported in previous works $[22,24]$ for identical specimens.

\section{Results and Discussion}

Microstructure of composites with $17 \mathrm{vol}$ \% GNP and $7 \mathrm{vol} \% \mathrm{rGO}$ are readily compared in Fig. 2, they basically consist of a fine grained $\mathrm{Si}_{3} \mathrm{~N}_{4}$ matrix with 
either GNPs or rGO sheets preferentially aligned (Fig. 2a,c) along the plane perpendicular to the vertical loading axis defined by the SPS consolidation process. As-synthesized GO sheets are thinner than GNPs such as denoted by SFM images of Fig. 2b,e and their corresponding depth profiles; the thickness difference between both graphene fillers is preserved in the consolidated composites. Consequently, $\mathrm{Si}_{3} \mathrm{~N}_{4}$ composites with rGO fillers have lower percolation limit for electrical conduction, evidenced by the lower concentration required $\sim 3$ vol.\% rGO against $\sim 7$ vol.\% for GNPs to achieve measurable electric conductivity, as it was fully discussed in previous works [22,25].

The higher exfoliation condition of rGO filler compared to GNPs is plainly reflected by the Raman images constructed by filtering the intensity ratio of the 2D $\left(\sim 2700 \mathrm{~cm}^{-1}\right)$ and $\mathrm{G}\left(\sim 1580 \mathrm{~cm}^{-1}\right)$ characteristic Raman bands of graphene, $\mathrm{I}_{2 \mathrm{D}} / \mathrm{I}_{\mathrm{G}}$, for each composite type, depicted particularly for the $21 \mathrm{vol}$. \% GNP and 7 vol. \% rGO composites in Fig. 3a,d. Actually, the occurrence of brighter zones of high intensity ratios $\left(\mathrm{I}_{2 \mathrm{D}} / \mathrm{IG}_{\mathrm{G}}>0.6\right)$ typical of $\mathrm{FLG}$ is more frequent for the $\mathrm{rGO}$ composite. Singular spectra with $I_{2 D / G}>1$ (Fig. 3 b,e) distinctive of single layer graphene [26] are also more frequent in the last material. The D peak in the Raman spectra appearing near $1355 \mathrm{~cm}^{-1}$ and reflecting the existence of defects is more intense in rGO composites as shown by the average Raman spectra (Fig. 3c,f), with an intensity ratio of the defects $D$ band to the $G$ band, $\mathrm{ID} / \mathrm{lG}$, of 0.42 as compared to $\mathrm{ID} / \mathrm{lg}$ of 0.22 for GNP composites. The more intense $\mathrm{D}$ band of $\mathrm{rGO}$ specimens is due to the existence of different functional groups not completely eliminated after the GO thermal reduction during the SPS of the composites. In fact, as stated in a previous work [25] the percentage of $\mathrm{C}-\mathrm{C}$ and $\mathrm{C}=\mathrm{C}$ bonds in the $\mathrm{rGO}$ structure reached $\sim 80.4 \%$, the rest 
corresponding to epoxy and hydroxyl bonds [27] although the presence of C-N bond cannot be discarded as it has similar binding energy as the $\mathrm{C}-\mathrm{OH}$ bond [25]. The high intensity of the $G$ band and the sharpness of the Raman peaks in the rGO composites compared to spectra normally observed for rGO obtained by chemical and/or more conventional thermal reduction [27] at temperatures below $1100{ }^{\circ} \mathrm{C}$ can be attributed to the drastic experimental conditions of the SPS [28].

The low voltage atomic resolution images in STEM mode of the $\mathrm{Si}_{3} \mathrm{~N}_{4}$ with 4 vol. $\%$ rGO composite (Fig. 4a) allows identifying the different phases according to the attached fast Fourier transforms (FFT). The thin rGO sheets, the $\mathrm{Si}_{3} \mathrm{~N}_{4}$ grain and the triple point (TP) amorphous phase, consistent with the liquid phase sintering process. The rGO sheets observed are FLG (4-10 layers), with a distance between atomic planes of $0.3 \mathrm{~nm}$ and with a certain degree of missorientation between the graphene planes (FFT in Fig. 4b). Closer examination of the large rGO film projecting from the interface with the $\mathrm{Si}_{3} \mathrm{~N}_{4}$ grain permits identification of typical defective zones at the edges of the rGO sheet, residues from the reduction process [27], but we can detect as well nano-clusters (2-5 $\mathrm{nm}$ ) of disordered/defective zones on the graphene plane (Fig. 4b) separated by less than $5 \mathrm{~nm}$. This picture is consistent with the structural models representing the reduction process in GO films, in which initial large zones having $\mathrm{O}$ bonds are reduced and isolated while $\mathrm{sp}^{2} \mathrm{C}$ bonds are progressively reconstructed. Actually, the high temperature SPS process allows a high degree of crystalline reconstruction of the graphene network in GO [29]. The temperature dependence of the thermoelectric power of $\mathrm{rGO} / \mathrm{Si}_{3} \mathrm{~N}_{4}$ and GNP/Si ${ }_{3} N_{4}$ composites are shown in Figure 5. Different signs of $\mathrm{S}$ are observed 
for rGO (-) and GNP (+) composites for the whole temperature range (100- 320 $\mathrm{K})$, showing both composites an increase in the absolute values of $S$ with temperature and a peak $\mathrm{S}$ value of $-25 \mu \mathrm{V} / \mathrm{K}$ at $320 \mathrm{~K}$ corresponding to the $\mathrm{Si}_{3} \mathrm{~N}_{4}-4$ vol.\% rGO composite, $\sim 4$ times higher than maximum $\mathrm{S}$ for GNP composites (Fig. 5, Table 1).

The room temperature $S$ values of the GNP composites, +5 and $+3.7 \mu \mathrm{V} . \mathrm{K}^{-1}$ (see Table 1) are within the range of values reported for flexible graphite paper, from -2.6 and to $+12 \mu \mathrm{V} \cdot \mathrm{K}^{-1}$ at $\sim 300 \mathrm{~K}$ [30-32], made by compressing exfoliated graphite flakes from expanded graphite -no data for ceramic composites with pristine GNP are available to compare. The $\mathrm{S}$ values for $\mathrm{rGO} / \mathrm{Si}_{3} \mathrm{~N}_{4}$ composites, -26 and $-24 \mu \mathrm{V} . \mathrm{K}^{-1}$, are relatively higher in absolute value than published data for various GO/Y-TZP composites [16,33] $\left(-15,+17\right.$ and $+22 \mu \mathrm{V} . \mathrm{K}^{-1}$ at $\left.300 \mathrm{~K}\right)$ and for $\mathrm{FLG} / \mathrm{Al}_{2} \mathrm{O}_{3}$ composite [33] (-17 $\mu \mathrm{V} . \mathrm{K}^{-1}$ at $\left.300 \mathrm{~K}\right)$, all reduced during sintering. Present values are also above the $S\left(+10 \mu \mathrm{V} . \mathrm{K}^{-1}\right)$ of rGO films above reported [11].

Given the linear temperature dependence of the thermopower in the composites (Fig. 5) and considering the sign of $\mathrm{S}$, we can assume that electric carriers are electrons for rGO composites and holes for the GNP types. The Hall effect measurement confirm these terms, see as example the result for the 4 vol.\% rGO composite in Fig. 6 . The corresponding carrier concentration gives values of $6.3 \times 10^{19} \mathrm{e} / \mathrm{cm}^{3}$ of hole carriers for $\mathrm{Si}_{3} \mathrm{~N}_{4}-17$ vol.\% GNP composite (p-type), and $8.6 \times 10^{19} \mathrm{e} / \mathrm{cm}^{3}$ of electron carriers for the $\mathrm{Si}_{3} \mathrm{~N}_{4}-4$ vol.\% rGO composite (n-type). Accordingly, the sign of the Seebeck coefficient in these composites is effectively determined by the carrier sign. Therefore, the higher $\mathrm{S}$ absolute 
values observed for rGO composites are not linked to a decrease in the carrier concentration, and then it has to be linked to other effects such as possible changes in the density of electronic states (DOS) near the Fermi level [16]. This effect can be attributed to oxygen functionalities or even some $\mathrm{N}$ doping of the graphene network and associated to the defective nanoclusters observed in the rGO sheet (Fig. 4), thus creating structural disorder and opening the band gap $[1,34]$. The possible $\mathrm{N}$ doping would be supported as well by the $\mathrm{n}$-type character often reported for $\mathrm{N}$-doped graphene monolayer [35].

PF for the different volume fractions were estimated at room temperature as shown in Table 2. The highest PF $\left(0.38 \mu \mathrm{W} \cdot \mathrm{m}^{-1} \cdot \mathrm{K}^{-2}\right)$ is observed for the $\mathrm{Si}_{3} \mathrm{~N}_{4}-7$ vol. \% rGO composite, around 6 times higher than composite with 4 vol.\% rGO, essentially due to its greater electrical conductivity (see Table 2). Comparing with GNP composites, increases of 17 times in the PF are observed, and as good as values reported for polyaniline (0.4-10) [14-15] and 3Y-TZP (0.12) [16] with GO fillers. The composite with top PF also has the highest $\mathrm{ZT}$ value $\left(0.09 \times 10^{-4}\right)$ although far from optimal $(Z T \geq 1)$ for practical uses.

Hence, thermoelectric characteristics of silicon nitride composites with rGO fillers are more relevant than those with GNPs as the lower $\sigma$ is compensated by the higher $\mathrm{S}$ and relatively lower $\kappa$ (Table 2). Reduction of $\mathrm{GO}$ fillers during the high temperature SPS process is effective for increasing the thermopower characteristics due to nanoclustering of defects (oxygen groups and $\mathrm{N}$ doping). Interestingly $\mathrm{p}$ - and $\mathrm{n}$ - doping are achieved in graphene $/ \mathrm{Si}_{3} \mathrm{~N}_{4}$ just by changing the type of graphene filler. Although these composites might not be competitive 
for practical uses, present findings are interesting starting point for further developments.

\section{Conclusions}

We demonstrated that graphene-Si $\mathrm{N}_{4}$ composites consolidated by SPS possess novel thermoelectric effect with different characteristics for thermally reduced graphene oxide and pristine graphene nanoplatelets. A peak thermopower of $-26 \mu \mathrm{V} . \mathrm{K}^{-1}$ at room temperature is achieved for the $\mathrm{Si}_{3} \mathrm{~N}_{4}-4$ vol.\% rGO composite, whereas a top $\mathrm{S}$ of $+5 \mu \mathrm{V} . \mathrm{K}^{-1}$ is reached for the $\mathrm{Si}_{3} \mathrm{~N}_{4}-17$ vol.\% GNP material. The rGO composites are n-type semiconductors and have electrons as the main current carrier whereas GNP composites are p-type with holes as native carriers. Carrier concentrations are in the order of $10^{19} \mathrm{e} / \mathrm{cm}^{3}$ for both composites and slightly higher for rGO composites, hence are not the cause of the differences in S. The comparatively higher thermoelectric power for rGO composites is attributed to the presence of defective nano-clusters in the graphene plane observed by STEM, linked to O/N functionalities that would affect the densities of states at the bandgap. The higher $\mathrm{S}$ of $\mathrm{rGO}$ composites is also accompanied by a larger PF $\left(0.38 \mu \mathrm{W} \cdot \mathrm{m}^{-1} \cdot \mathrm{K}^{-2}\right)$ and ZT number.

\section{Acknowledgements}

This research has been supported by MINECO and CSIC (Spain) under projects MAT2012-32944 and PIE 201360E063, respectively. F.R. acknowledges the European Research Council (ERC StG-259082, 2DTHERMS), and MINECO of Spain (MAT2013-44673-R). STEM/TEM studies have been done in the CNME (UCM, Madrid), special thanks are given to Dr. Almudena Torres and Dr. M. Luisa Gonzalez for their important contribution in this respect. 
Table 1. Thermoelectric power at room temperature for different composites

\begin{tabular}{ll}
\hline sample & $\mathbf{S}(\boldsymbol{\mu V} / \mathbf{K})$ at $300 \mathrm{~K}$ \\
\hline $\mathrm{Si}_{3} \mathrm{~N}_{4}-4 \mathrm{vol} \% \mathrm{rGO}$ & -25 \\
$\mathrm{Si}_{3} \mathrm{~N}_{4}-7 \mathrm{vol} \% \mathrm{rGO}$ & -23.6 \\
$\mathrm{Si}_{3} \mathrm{~N}_{4}-17 \mathrm{vol} \% \mathrm{GNP}$ & 5.0 \\
$\mathrm{Si}_{3} \mathrm{~N}_{4}-21 \mathrm{vol} \% \mathrm{GNP}$ & 3.7 \\
\hline
\end{tabular}


Table 2. Thermal conductivity $(\kappa)$, electrical conductivity $(\sigma)$, power factor (PF) and figure of merit (ZT) for the different composites al 300K.

\begin{tabular}{|c|c|c|c|c|}
\hline sample & $\begin{array}{l}\kappa^{22} \\
\left(W \cdot m^{-1} \cdot K^{-1}\right)\end{array}$ & $\begin{array}{l}\sigma^{24} \\
\left(\mathrm{~S} . \mathrm{m}^{-1}\right)\end{array}$ & $\begin{array}{l}\text { PF } \\
\left(\mu W \cdot m^{-1} \cdot K^{-2}\right)\end{array}$ & ZT $\times 10^{-4}$ \\
\hline $\mathrm{Si}_{3} \mathrm{~N}_{4}-4$ vol.\% rGO & 14.8 & 90 & 0.06 & 0.012 \\
\hline $\mathrm{Si}_{3} \mathrm{~N}_{4}-7$ vol.\% rGO & 12.3 & 690 & 0.38 & 0.09 \\
\hline $\mathrm{Si}_{3} \mathrm{~N}_{4}-17$ vol. $\%$ GNP & 38.5 & 908 & 0.022 & 0.002 \\
\hline $\mathrm{Si}_{3} \mathrm{~N}_{4}-21$ vol. $\%$ GNP & 44.0 & 2020 & 0.027 & 0.002 \\
\hline
\end{tabular}




\section{References}

1. J. R. Sootsman, D. Y. Chung, and M. G. Kanatzidis, "New and Old Concepts in Thermoelectric Materials," Angewandte Chemie-International Edition, 48[46] 8616-39 (2009).

2. K. Biswas, J. Q. He, I. D. Blum, C. I. Wu, T. P. Hogan, D. N. Seidman, V. P. Dravid, and M. G. Kanatzidis, "High-performance bulk thermoelectrics with all-scale hierarchical architectures," Nature, 489[7416] 414-18 (2012).

3. K. Koumoto, R. Funahashi, E. Guilmeau, Y. Miyazaki, A. Weidenkaff, Y. Wang, and C. Wan, "Thermoelectric Ceramics for Energy Harvesting," Journal of the American Ceramic Society, 96[1] 1-23 (2013).

4. A. Geim and K. Novoselov, "The rise of graphene," Nat. Mater., 6[3] 183-91 (2007).

5. Y. Xu, Z. Li, and W. Duan, "Thermal and Thermoelectric Properties of Graphene," Small, 10[11] 2182-99 (2014).

6. J. H. Seol, I. Jo, A. L. Moore, L. Lindsay, Z. H. Aitken, M. T. Pettes, X. Li, Z. Yao, R. Huang, D. Broido, N. Mingo, R. S. Ruoff, and L. Shi, "Two-Dimensional Phonon Transport in Supported Graphene," Science, 328[5975] 213-16 (2010).

7. A. A. Balandin, "Thermal properties of graphene and nanostructured carbon materials," Nat. Mater., 10[8] 569-81 (2011).

8. F. Bonaccorso, L. Colombo, G. Yu, M. Stoller, V. Tozzini, A. C. Ferrari, R. S. Ruoff, and V. Pellegrini, "Graphene, related two-dimensional crystals, and hybrid systems for energy conversion and storage," Science, 347[6217] (2015).

9. J. Y. Kim and J. C. Grossman, "High-Efficiency Thermoelectrics with Functionalized Graphene," Nano Lett., 15[5] 2830-35 (2015).

10. N. Xiao, X. Dong, L. Song, D. Liu, Y. Tay, S. Wu, L.-J. Li, Y. Zhao, T. Yu, H. Zhang, W. Huang, H. H. Hng, P. M. Ajayan, and Q. Yan, "Enhanced Thermopower of Graphene Films with Oxygen Plasma Treatment," ACS Nano, 5[4] 2749-55 (2011).

11. J. Choi, N. D. K. Tu, S.-S. Lee, H. Lee, J. S. Kim, and H. Kim, "Controlled oxidation level of reduced graphene oxides and its effect on thermoelectric properties," Macromolecular Research, 22[10] 1104-08 (2014).

12. S. Stankovich, D. A. Dikin, G. H. B. Dommett, K. M. Kohlhaas, E. J. Zimney, E. A. Stach, R. D. Piner, S. T. Nguyen, and R. S. Ruoff, "Graphene-based composite materials," Nature, 442[7100] 282-86 (2006).

13. Y. C. Fan, L. J. Wang, J. L. Li, J. Q. Li, S. K. Sun, F. Chen, L. D. Chen, and W. Jiang, "Preparation and electrical properties of graphene nanosheet/Al2O3 composites," Carbon, 48[6] 1743-49 (2010).

14. B. Abad, I. Alda, P. Diaz-Chao, H. Kawakami, A. Almarza, D. Amantia, D. Gutierrez, L. Aubouy, and M. Martin-Gonzalez, "Improved power factor of polyaniline nanocomposites with exfoliated graphene nanoplatelets (GNPs)," Journal of Materials Chemistry A, 1[35] 10450-57 (2013).

15. Y. Zhao, G. S. Tang, Z. Z. Yu, and J. S. Qi, "The effect of graphite oxide on the thermoelectric properties of polyaniline," Carbon, 50[8] 3064-73 (2012).

16. M. Estili, W.-W. Wu, M. Khazaei, and Y. Sakka, "Mechanically reliable thermoelectric (TE) nanocomposites by dispersing and embedding TE-nanostructures inside a tetragonal ZrO2 matrix: the concept and experimental demonstration in graphene oxide-3YSZ system," Science and Technology of Advanced Materials, 15[1] (2014).

17. G. D. Zhan, J. D. Kuntz, A. K. Mukherjee, P. X. Zhu, and K. Koumoto, "Thermoelectric properties of carbon nanotube/ceramic nanocomposites," Scripta Materialia, 54[1] 7782 (2006).

18. D. Chen, Y. Zhao, Y. Chen, B. Wang, H. Chen, J. Zhou, and Z. Liang, "One-Step Chemical Synthesis of $\mathrm{ZnO} /$ Graphene Oxide Molecular Hybrids for High-Temperature Thermoelectric Applications," Acs Applied Materials \& Interfaces, 7[5] 3224-30 (2015). 
19. Y. Lin, C. Norman, D. Srivastava, F. Azough, L. Wang, M. Robbins, K. Simpson, , R. Freer and I. A. Kinloch, "Thermoelectric Power Generation from Lanthanum Strontium Titanium Oxide at Room Temperature through the Addition of Graphene", ACS Appl. Mater. Interfaces 7 15898-159085 (2015).

20. C. Ramirez, P. Miranzo, M. Belmonte, M. I. Osendi, P. Poza, S. M. Vega-Diaz, and M. Terrones, "Extraordinary toughening enhancement and flexural strength in $\mathrm{Si}_{3} \mathrm{~N}_{4}$ composites using graphene sheets," Journal of the European Ceramic Society, 34 1619 (2014).

21. J. Dusza, J. Morgiel, A. Duszova, L. Kvetkova, M. Nosko, P. Kun, and C. Balazsi, "Microstructure and fracture toughness of Si3N4 + graphene platelet composites," Journal of the European Ceramic Society, 32[12] 3389-97 (2012).

22. C. Ramirez, F. M. Figueiredo, P. Miranzo, P. Poza, and M. Isabel Osendi, "Graphene nanoplatelet/silicon nitride composites with high electrical conductivity," Carbon, 50[10] 3607-15 (2012).

23. C. Ramirez, L. Garzon, P. Miranzo, M. I. Osendi, and C. Ocal, "Electrical conductivity maps in graphene nanoplatelet/silicon nitride composites using conducting scanning force microscopy," Carbon, 49[12] 3873-80 (2011).

24. P. Miranzo, E. Garcia, C. Ramirez, J. Gonzalez-Julian, M. Belmonte, and M. Isabel Osendi, "Anisotropic thermal conductivity of silicon nitride ceramics containing carbon nanostructures," Journal of the European Ceramic Society, 32[8] 1847-54 (2012).

25. C. Ramirez, S. M. Vega-Diaz, A. Morelos-Gomez, F. M. Figueiredo, M. Terrones, M. I. Osendi, M. Belmonte, and P. Miranzo, "Synthesis of conducting graphene/Si3N4 composites by spark plasma sintering," Carbon, 57 425-32 (2013).

26. Y. Y. Wang, Z. H. Ni, T. Yu, Z. X. Shen, H. M. Wang, Y. H. Wu, W. Chen, and A. T. S. Wee, "Raman studies of monolayer graphene: The substrate effect," Journal of Physical Chemistry C, 112[29] 10637-40 (2008).

27. S. Mao, H. Pu, and J. Chen, "Graphene oxide and its reduction: modeling and experimental progress," RSC Advances, 2[7] 2643-62 (2012).

28. Y. Zhang, D. Li, X. Tan, B. Zhang, X. Ruan, H. Liu, C. Pan, L. Liao, T. Zhai, Y. Bando, S. Chen, W. Cai, and R. S. Ruoff, "High quality graphene sheets from graphene oxide by hotpressing," Carbon, 54 143-48 (2013).

29. W. Gao, L. B. Alemany, L. Ci, and P. M. Ajayan, "New insights into the structure and reduction of graphite oxide," Nature Chemistry, 1[5] 403-08 (2009).

30. C. Uher, "Thermopower of exfoliated graphites between 1.7-K and 300-K," Physical Review $B, 25[6]$ 4167-72 (1982).

31. Y. M. Hoi and D. D. L. Chun, "Flexible graphite as a compliant thermoelectric material," Carbon, 40[7] 1134-36 (2002).

32. M. Rastegaralam, M. Piao, G. Kim, U. Dettlaff-Weglikowska, and S. Roth, "Influence of chemical treatment on the electrical conductivity and thermopower of expanded graphite foils," Physica Status Solidi C: Current Topics in Solid State Physics, Vol 10, No 7-8, 10[7-8] 1183-87 (2013).

33. Y. Fan, L. Kang, Weiwei Zhou, W. Jiang, L. Wang, A. Kawasaki, “Control of doping by matrix in few-layer graphene/metal oxide composites with highly enhanced electrical conductivity", Carbon 81, 83-9, (2015).

34. J.-H. Lee, J. Wu, and J. C. Grossman, "Enhancing the thermoelectric power factor with highly mismatched isoelectronic doping," Physical Review Letters, 104[1] 016602-5 (2010).

35. D. Wei, Y. Liu,, Y. Wang', H. Zhang', L. Huang and G. Yu, "Synthesis of N-doped graphene by chemical vapor deposition and its electrical properties" Nano Lett., 9 [5] 1752-8, 2009. 
Figure Captions

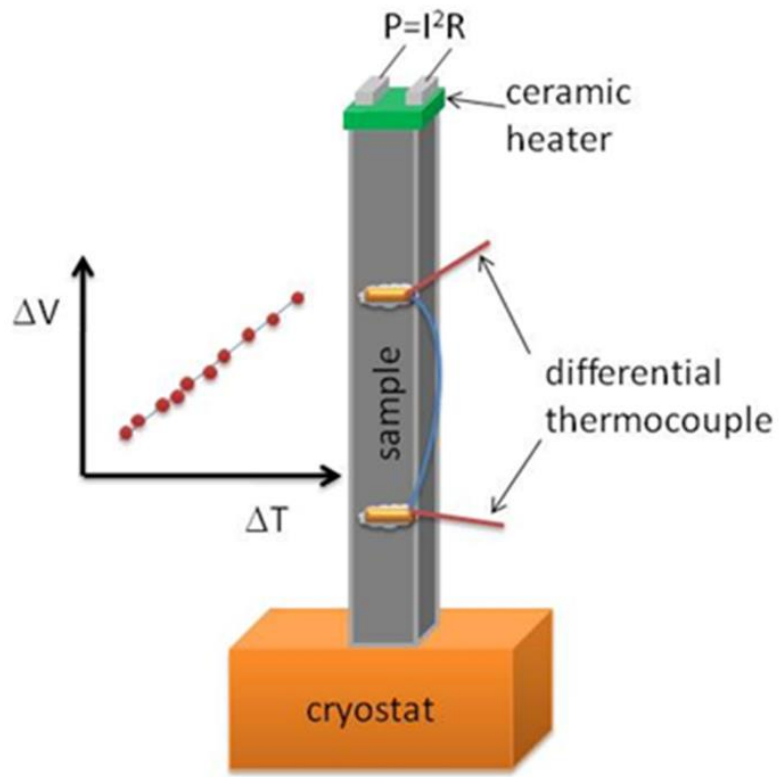

Figure 1. Schematic of experimental setting for Seebeck measurement 
a)

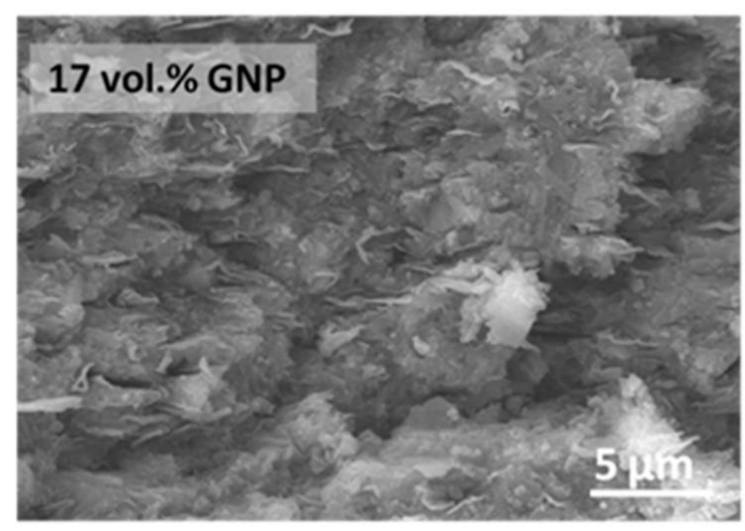

c)

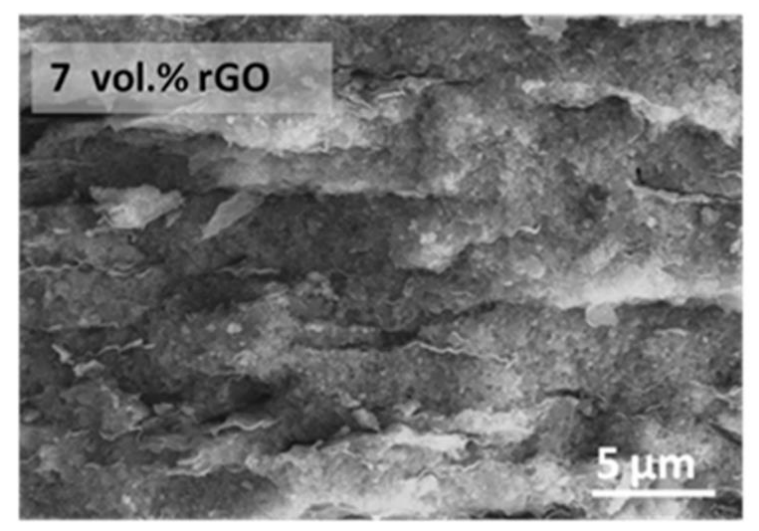

b)

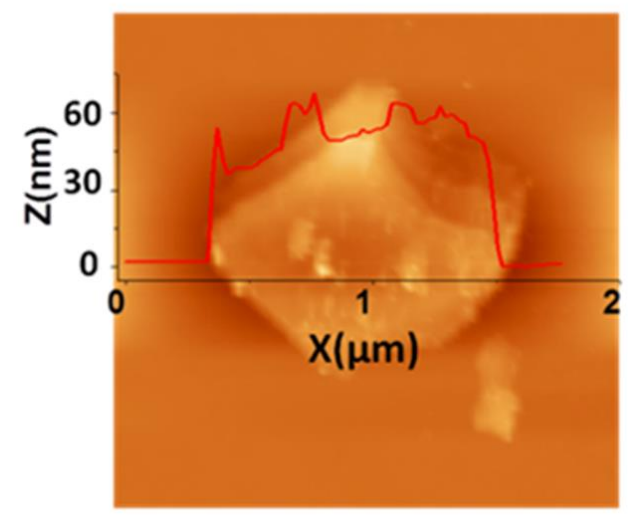

d)

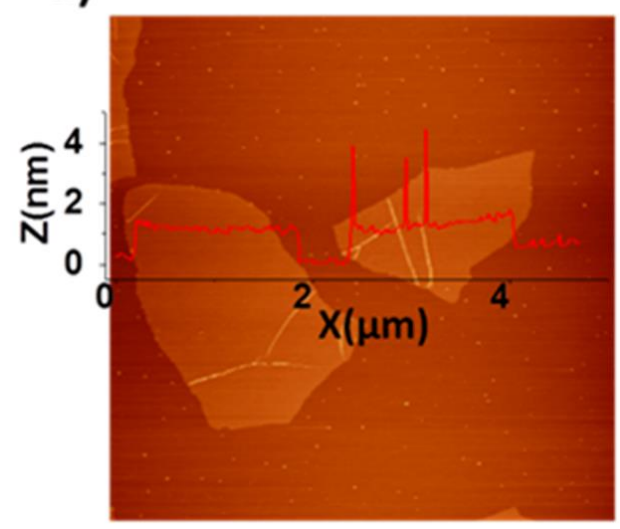

Figure 2. Panel showing representative microstructures of the composites and the GRMs. (a) Fracture surface GNP composite (17 vol.\%) where graphene nanostructures are identified protruding from the surface and with a preferential horizontal orientation, (b) SFM image of original GNPs dispersed and corresponding depth profile, (c) fracture surface rGO composite (7 vol.\%) with undulating and oriented rGO sheets (d) SFM image of as-synthesized with dispersed GO and corresponding depth profile. 
a) 21 vol.\% GNP

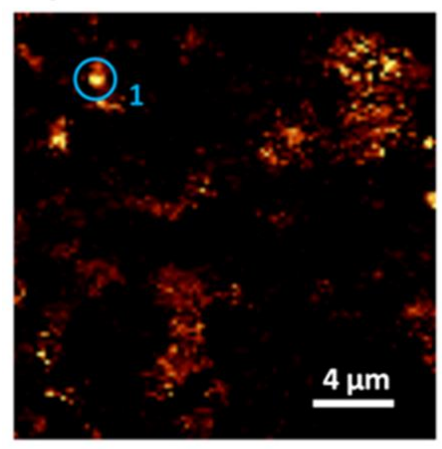

d) 7 vol.\% rGo

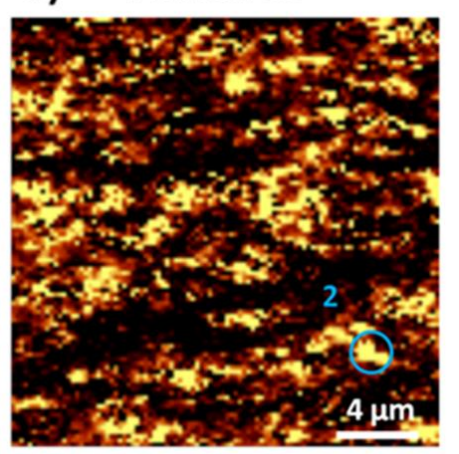

b)

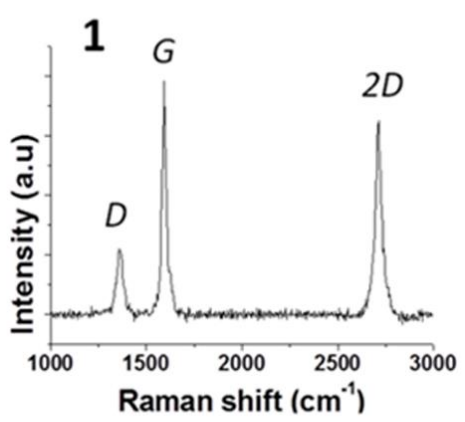

e)

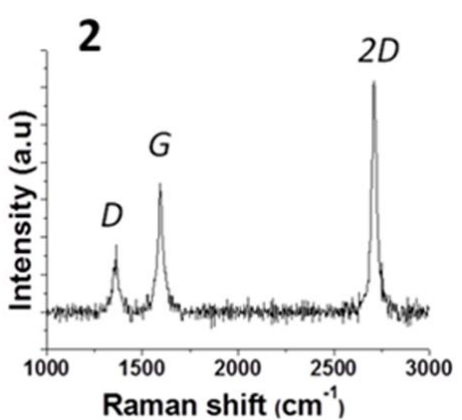

c)

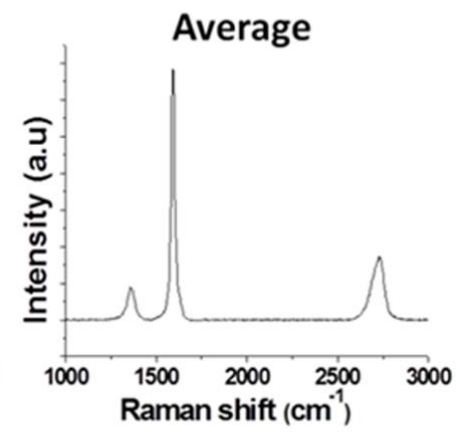

f)

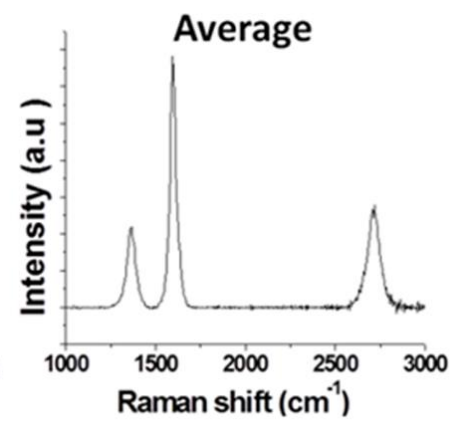

Figure 3. (a) Raman image constructed by filtering the 2D graphene signal normalized by the intensity of the $G$ band, i.e. mapping of $I_{2 D} / I_{G}$ signal with scale variation from 0.2 to $>0.6$ for the $\mathrm{Si}_{3} \mathrm{~N}_{4} / 21$ vol. \% GNP composite, (b) single spectra of intense spot circled in (a) image, (c) average spectra of the whole area in (a) image,(d) same construction as in (a) for $\mathrm{Si}_{3} \mathrm{~N}_{4} / 7$ vol. \% rGO composite, (d) single spectra of intense spot circled in (d) image, (e) average spectra of the whole area in (d) image. 
a)

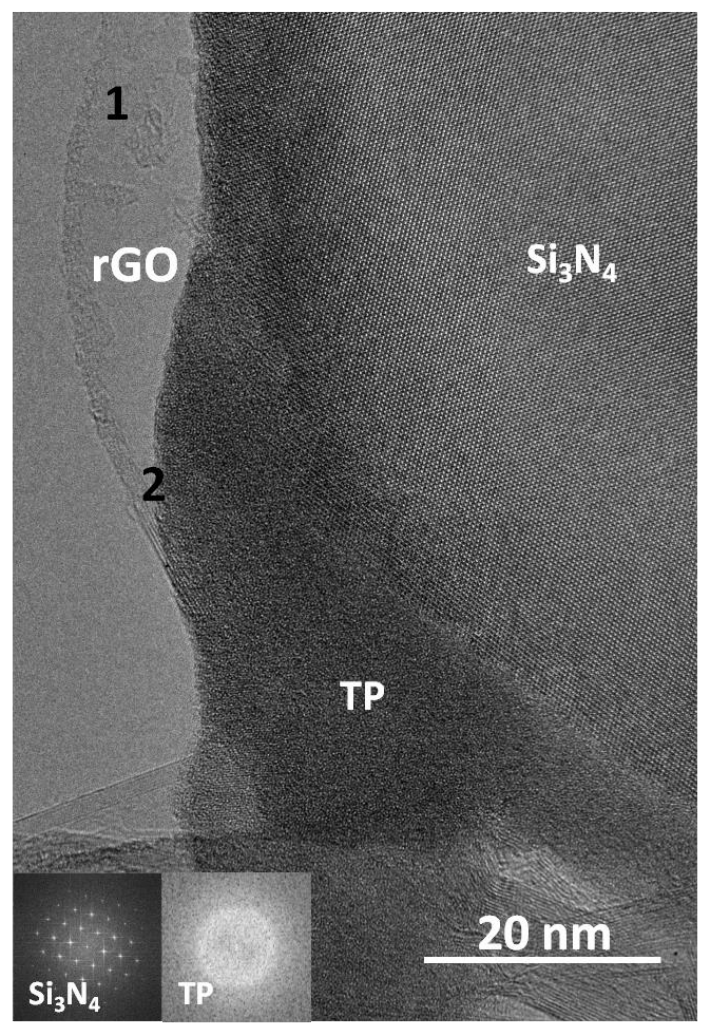

b)
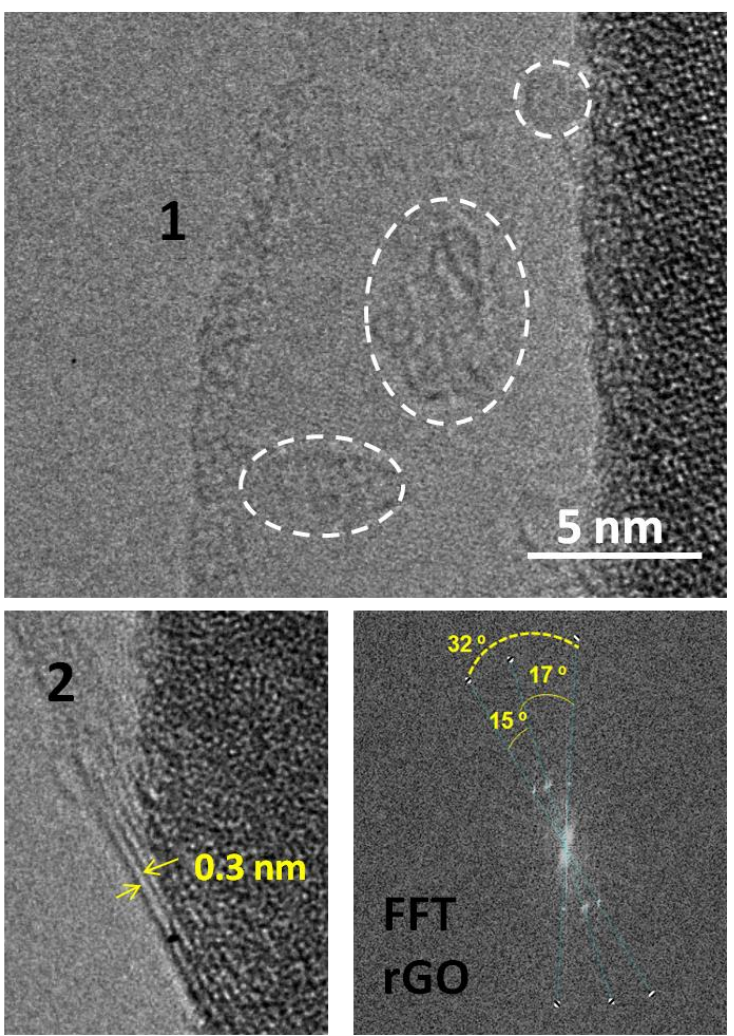

Figure 4. (a) STEM image of $7 \mathrm{vol}$ \% rGO composite showing the ab graphene plane of a rGO sheet, $\mathrm{Si}_{3} \mathrm{~N}_{4}$ grain and amorphous triple point with corresponding local FFT.

(b) Details of rGO sheet. Above: Disordered defective regions (1) are observed at the edge of the rGO sheet and also on the ab plane, appearing encircled in the image. Below: Magnification of the edge (2) showing that rGO sheet is a stack of 4 layers rotated with respect to each other (FFT). 


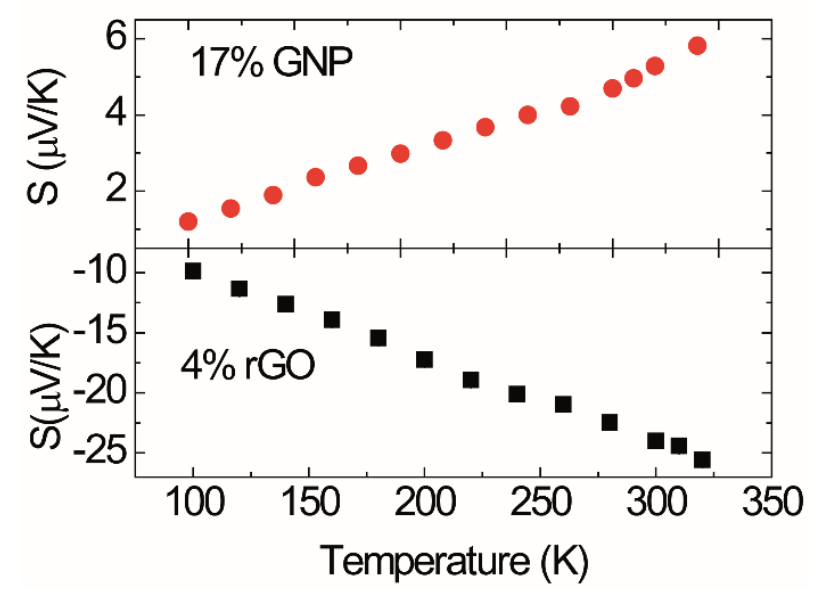

Figure 5. Low temperature Seebeck coefficient for $\mathrm{Si}_{3} \mathrm{~N}_{4}$ composites with $17 \mathrm{vol}$. \% of GNPs and 4 vol. \% rGO.

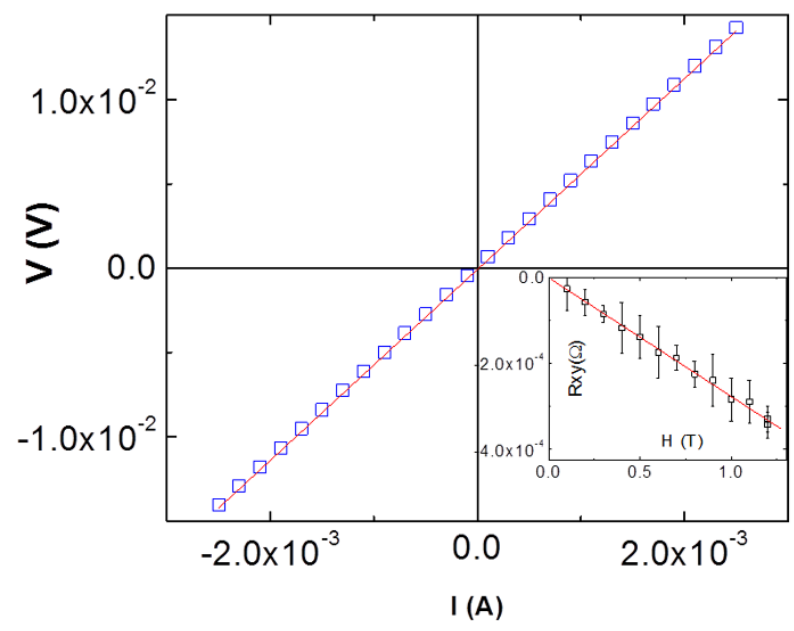

Figure 6. I/V curve of the 4.3 vol.\% composite measured in Van der Paw configuration. The inset shows the Hall resistance as a function of the magnetic field. 